ISSN 2073-4352

www.mdpi.com/journal/crystals

Article

\title{
Organic Semiconductors and Conductors with tert-Butyl Substituents
}

\author{
Toshiki Higashino, Yuto Akiyama, Hirotaka Kojima, Tadashi Kawamoto and Takehiko Mori * \\ Department of Organic and Polymeric Materials, Tokyo Institute of Technology, O-okayama 2-12-1, \\ Meguro-ku, Tokyo 152-8552, Japan; E-Mails: higashino.t.aa@m.titech.ac.jp (T.H.); \\ akiyama.y.ad@m.titech.ac.jp (Y.A.); kojima.h.ab@m.titech.ac.jp (H.K.); \\ kawamoto@o.cc.titech.ac.jp (T.K.)
}

* Author to whom correspondence should be addressed; E-Mail: mori.t.ae@ m.titech.ac.jp;

Tel./Fax: +81-3-5734-2427.

Received: 12 May 2012; in revised form: 30 July 2012 / Accepted: 30 July 2012 /

Published: 22 August 2012

\begin{abstract}
Tetrathiafulvalene (TTF), pentacene, and quarterthiophene with tert-butyl substituents are synthesized, and the crystal structures and the transistor properties are investigated. The tetracyanoquinodimethane (TCNQ) complex of tert-butyl TTF constructs highly one-dimensional segregated columns with tetragonal crystal symmetry.
\end{abstract}

Keywords: organic transistors; organic semiconductors; crystal structures

\section{Introduction}

Tight crystal packing is an important factor to achieve good transport in molecular conductors, because intermolecular interaction is easily interrupted by the introduction of sterically bulky groups. However, for example, the ethylene parts of bis(ethylenedithio)tetrathiafulvalene (BEDT-TTF) are indispensable groups to realize the two-dimensional transport, by balancing the transport in the stacking and the inter-stacking directions. Recently, we have found that organic field-effect transistor (OFET) properties of TTF derivatives are much stabilized and improved by the introduction of tert-butyl groups [1]; examples are HMTTF (hexamethylene-TTF) [2], OMTTF (octamethylene-TTF) [3], and DBTTF (dibenzo-TTF) (Figure 1) [4]. Since these TTF derivatives are very strong organic donors, it is comparatively difficult to attain a small threshold voltage $V_{\text {th }}$ and long-term stability, though HMTTF and DBTTF show high mobility exceeding $1 \mathrm{~cm}^{2} \mathrm{~V}^{-1} \mathrm{~s}^{-1}$ [5-8]. In these materials, the 
tert-butyl groups work like a passivation layer, where $V_{\text {th }}$ drastically goes down to $0 \mathrm{~V}$, and the transistors maintain the stable operation even after several months, without changing the energy levels. Interestingly, other $s$ - and $n$-alkyl groups do not show similar effects. Prompted by these findings, we have synthesized tert-butyl substituted TTF (1); pentacene (2); and quarterthiophene (4T, 3) molecules (Figure 1), and investigated the structural and transistor properties. The former two are new compounds, though several alkyl-substituted TTF and pentacene molecules have been reported [9-12]. Although alkyl-substituted oligothiophenes have been extensively studied [13], the tert-butyl substituted $4 \mathrm{~T}$ has been studied to some extent only in the $S$-dioxide form [14]. We have also investigated the structural and conducting properties of the TCNQ complex of (1).

Figure 1. Molecular structures of organic semiconductors with tert-butyl substituents.

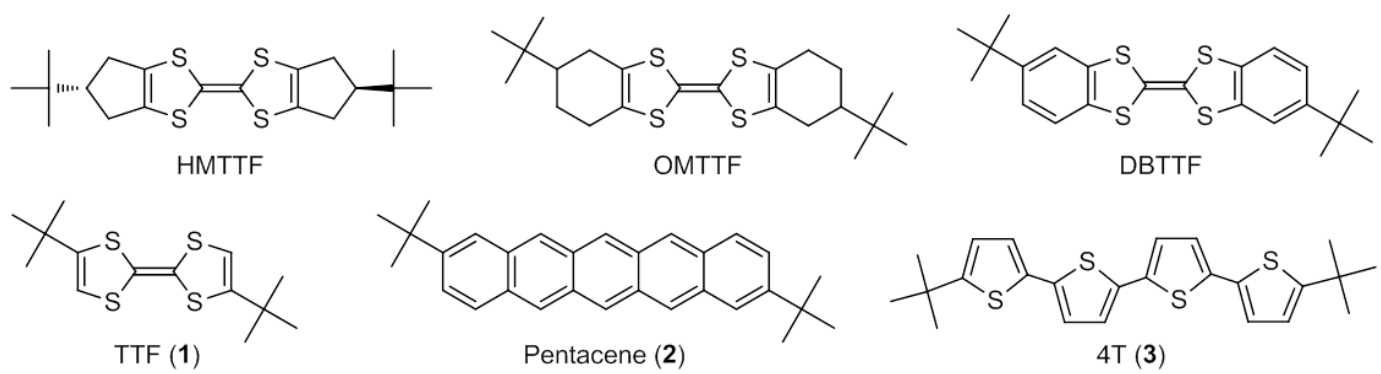

\section{Results and Discussion}

\subsection{Synthesis}

Synthesis of tert-butyl substituted TTF (1) was achieved as shown in Scheme 1 [2,3]. The reaction of 1-chloro-3,3-dimethylbutan-2-one with potassium isopropylxanthate, followed by cyclization with sulfuric acid, afforded 4-tert-butyl-1,3-dithiol-2-one (5), which was coupled by triethylphosphite to give 4,4'-di-tert-butyl-tetrathiafulvalene (1) [15]. This phosphite-mediated coupling reaction potentially produced $E$ - and Z-isomers with respect to the tert-butyl groups, but we can isolate a single isomer after repeated recrystallization from ethanol, which was verified by the X-ray crystal structure analysis. This compound is highly soluble in organic solvents; it dissolves even in hot hexane and in hot ethanol.

Scheme 1. Synthetic scheme for tert-butyl substituted Tetrathiafulvalene (TTF) (1).

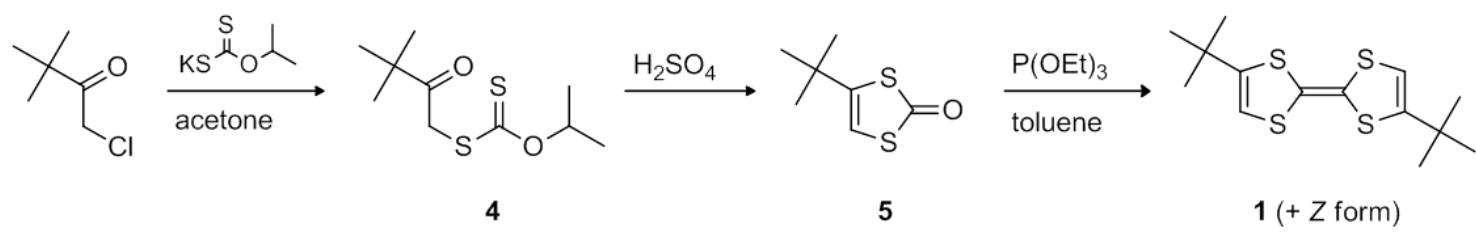

Synthesis of tert-butyl substituted pentacene (2) was attempted according to Scheme 2. Acylation of tert-butylbenzene with pyromellitic dianhydride afforded di(p-benzoyl)benzene (9) [16,17], which was cyclized by sulfuric acid to give tert-butyl substituted pentacene diquinone (10). Compound (2) was, however, not obtained by the reduction of (10) with sodium borohydride or lithium aluminium hydride, though there were reports on the reduction of (10) with aluminum amalgam [18] and the reduction of (9) with palladium carbon under $\mathrm{H}_{2}$ atmosphere [11]. 
Scheme 2. Attempted synthetic scheme for (2).

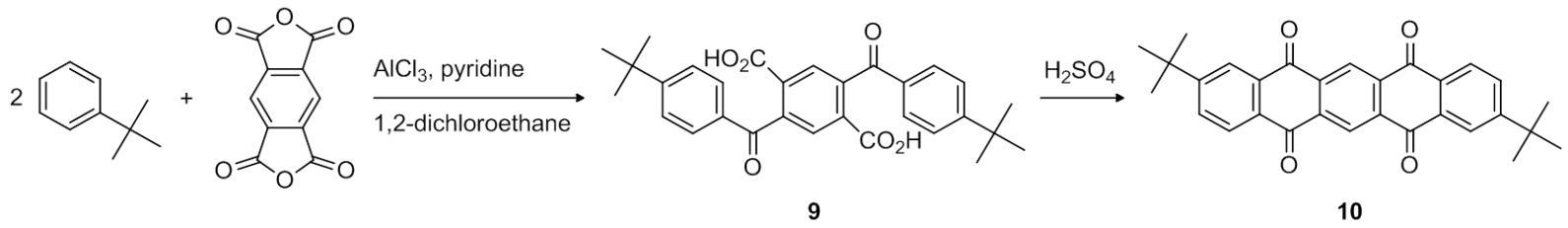

Then synthesis of tert-butyl substituted pentacene (2) was achieved via the route shown in Scheme 3 [19]. tert-Butyl substituted pentacene quinone (8) was obtained from 4-tert-butyl-1, 2-dimethyl-benzene by bromination with $N$-bromosuccinimide (NBS), followed by hydrolysis with a dimethylamine aqueous solution and the successive Aldol reaction with 1,4-cyclohexanedione under basic conditions. This reaction potentially produced $E$ - and $Z$-isomers, so we isolated a single isomer after repeated recrystallization from ethyl acetate. The resulting $(\mathbf{8})$ was reduced with lithium aluminium hydride, and the subsequent hydrochloric acid treatment afforded 2,9-di-tert-butyl-pentacene (2) [20].

Scheme 3. Synthetic scheme for tert-butyl substituted pentacene (2).
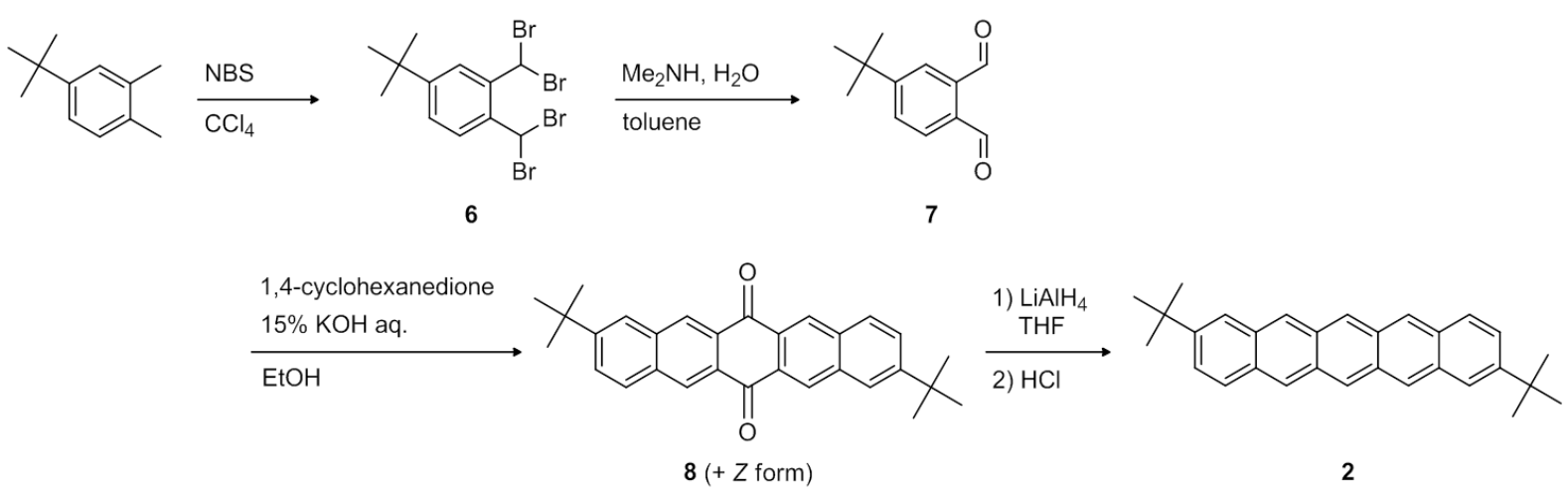

Synthesis of tert-butyl substituted quarterthiophene (3) was achieved as shown in Scheme 4 [21-23]. 2-Bromo-5-tert-butylthiophene (12) was obtained by the low-temperature Friedel-Crafts alkylation of thiophene with tert-butylchloride [3,21], followed by the bromination with NBS at 5-position. After the Stille coupling of (12) with 2-(tributylstannyl)thiophene, the homo coupling reaction with lithium diisopropylamine and copper(II) chloride finally gave $\alpha, \omega$-di-tert-butyl-quaterthiophene (3). This compound shows much improved solubility compared with the parent $4 \mathrm{~T}$.

Scheme 4. Synthetic scheme for tert-butyl substituted quarterthiophene (3).

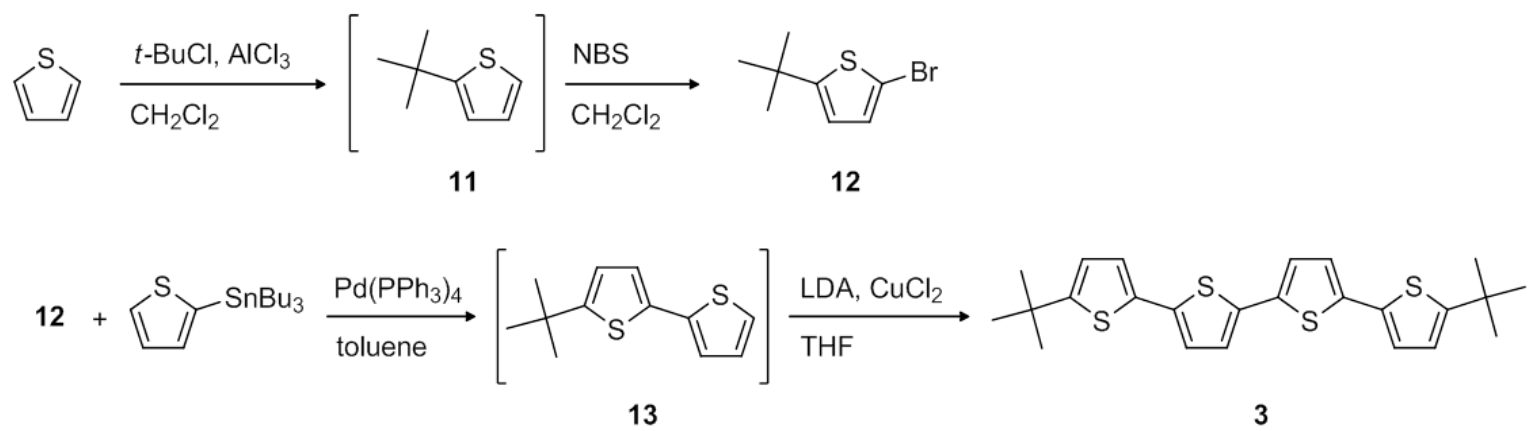




\subsection{Electrochemical and Optical Properties}

The electrochemical and optical properties have been investigated by cyclic voltammetry (CV) and ultraviolet/visible (UV/vis) absorption measurements as shown in Table 1. The energy gap is estimated from the absorption edge. The highest occupied molecular orbital (HOMO) energy is obtained from half-wave oxidation potential $E_{1 / 2}{ }^{1}[24,25]$, and the lowest unoccupied molecular orbital (LUMO) energy is estimated by adding the energy gap to the HOMO energy [26]. Table 1 lists the results of density functional theory (DFT) calculations by Gaussian 09 program at the level of B3LYP using the 6-31G(d,p) basis set as well [27]. Since the solubility in organic solvents is improved for all compounds by the tert-butyl substitution, CV of these compounds including (2) and (3) are easily measured at room temperature. All compounds show two reversible oxidation peaks, indicating two one-electron transfers. The theoretically calculated HOMOs approximately coincide with the experimentally obtained HOMOs. The substituted compounds have slightly higher HOMOs than the unsubstituted materials owing to the electron donating alkyl groups.

Table 1. Redox potentials ( $v s . \mathrm{SCE}^{a}$ : saturated calomel electrode), optical gaps, and the experimentally estimated and calculated highest occupied molecular orbital (HOMO) and lowest unoccupied molecular orbital (LUMO) energies.

\begin{tabular}{|c|c|c|c|c|c|c|c|}
\hline \multirow[t]{2}{*}{ Compounds } & \multicolumn{5}{|c|}{ Experiments } & \multicolumn{2}{|c|}{ Calculation } \\
\hline & $\begin{array}{c}E_{1 / 2}^{1} \\
(V)\end{array}$ & $\begin{array}{r}E_{1 / 2}^{2} \\
(V)\end{array}$ & $\begin{array}{l}\text { Gap } \\
(\mathrm{eV})\end{array}$ & $\begin{array}{c}\text { HOMO } \\
(\mathrm{eV})\end{array}$ & $\begin{array}{c}\text { LUMO } \\
(\mathrm{eV})\end{array}$ & $\begin{array}{c}\text { HOMO } \\
(\mathrm{eV})\end{array}$ & $\begin{array}{c}\text { LUMO } \\
(\mathrm{eV})\end{array}$ \\
\hline 1 & 0.16 & 0.70 & 3.20 & -4.56 & -1.36 & -4.40 & -0.70 \\
\hline 2 & 0.63 & 1.04 & 2.09 & -5.03 & -2.94 & -4.49 & -2.29 \\
\hline 3 & 0.75 & 0.99 & 2.68 & -5.15 & -2.47 & -4.83 & -1.76 \\
\hline TTF & 0.22 & 0.73 & 3.06 & -4.62 & -1.56 & -4.57 & -0.92 \\
\hline Pentacene & - & - & - & $-5.0^{b}$ & $-3.2^{b}$ & -4.61 & -2.40 \\
\hline $4 \mathrm{~T}$ & 0.78 & - & 2.74 & -5.18 & -2.44 & -4.97 & -1.94 \\
\hline
\end{tabular}

${ }^{a} \mathrm{Fc} / \mathrm{Fc}^{+} 0.40 \mathrm{~V}$ vs. SCE and $-4.80 \mathrm{eV}$ to vacuum; ${ }^{b}$ From [28].

\subsection{Single-Crystal X-ray Structure Analysis}

Single-crystal X-ray structure analyses were carried out for $\mathbf{1}$ and $\mathbf{2}$. The crystals were obtained by crystallization from hexane for $\mathbf{1}$ and by sublimation for $\mathbf{2}$. Table 2 shows the crystallographic data together with those of the unsubstituted TTF and pentacene [29,30]. The tert-butyl derivatives have entirely different structures from the parent compounds. A unit cell contains two molecules for all crystals. The lattice volumes are, however, approximately doubled by the tert-butyl substitution, indicating that the volume of each molecule is doubled, though the molecular weights are not increased so much. As a consequence, the density is considerably reduced due to the loose packing of the tert-butyl substituted molecules.

The crystal structures are depicted in Figures 2 and 3. The molecules are located on inversion centers, and a half of the molecule is crystallographically independent. There is no disorder on the tertbutyl position, so the crystals of both compounds contain only the $E$-isomers. Temperature factors of the tert-butyl groups are, however, considerably large due to the thermal motion and rotation. The TTF and pentacene skeletons are almost planar. 
Table 2. Crystallographic data for TTF, 1, pentacene, and 2.

\begin{tabular}{ccccc}
\hline & TTF [29] & $\mathbf{1}$ & Pentacene [30] & $\mathbf{2}$ \\
\hline Empirical formula & $\mathrm{C}_{2} \mathrm{H}_{4} \mathrm{~S}_{4}$ & $\mathrm{C}_{14} \mathrm{H}_{20} \mathrm{~S}_{4}$ & $\mathrm{C}_{22} \mathrm{H}_{14}$ & $\mathrm{C}_{30} \mathrm{H}_{30}$ \\
Formula weight & 204.33 & 316.55 & 278.35 & 390.57 \\
Temperature $(\mathrm{K})$ & 290 & 173 & 293 & 173 \\
Crystal system & monoclinic & monoclinic & triclinic & monoclinic \\
Space group & $P 2_{1} / c$ & $P 2_{1} / a$ & $P-1$ & $P 2_{1} / a$ \\
$\alpha(\AA)$ & $7.352(2)$ & $9.2639(2)$ & $6.266(1)$ & $10.8100(2)$ \\
$b(\AA)$ & $4.0181(11)$ & $9.7388(3)$ & $7.775(1)$ & $6.3668(2)$ \\
$c(\AA)$ & $13.901(4)$ & $9.3381(2)$ & $14.530(1)$ & $16.1783(4)$ \\
$\alpha\left({ }^{\circ}\right)$ & 90 & 90 & $76.475(4)$ & 90 \\
$\beta\left(^{\circ}\right)$ & $101.426(10)$ & $103.263(2)$ & $87.682(4)$ & $97.483(1)$ \\
$\gamma\left({ }^{\circ}\right)$ & 90 & 90 & $84.684(4)$ & 90 \\
$V\left(\AA^{3}\right)$ & $402.5(2)$ & $820.01(4)$ & $685.15(15)$ & $1111.24(4)$ \\
$Z$ & 2 & 2 & 2 & 2 \\
$D_{\text {calc }}\left(\mathrm{g} / \mathrm{cm}^{3}\right)$ & 1.686 & 1.282 & 1.349 & 1.167 \\
Reflections (unique) & $3571(926)$ & $8389(1501)$ & $2856(2684)$ & $12341(2033)$ \\
$R_{1}$ & 0.028 & 0.0768 & 0.069 & 0.0561 \\
$R_{\mathrm{w}}$ & 0.065 & 0.2215 & 0.179 & 0.1925 \\
$\mathrm{GOF}$ & 1.12 & 1.05 & 0.94 & 1.08 \\
\hline
\end{tabular}

Figure 2. Crystal structure of 1. (a) Top and side views of the molecular structure; (b) view perpendicular to the molecular plane (hydrogen atoms are not shown); and (c) projection along the molecular long axis (tert-butyl groups are not shown). Anisotropic displacement ellipsoids are drawn at the $50 \%$ probability level.

(a)

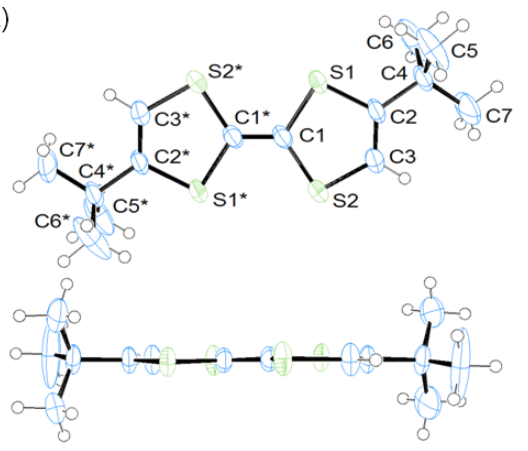

(b)

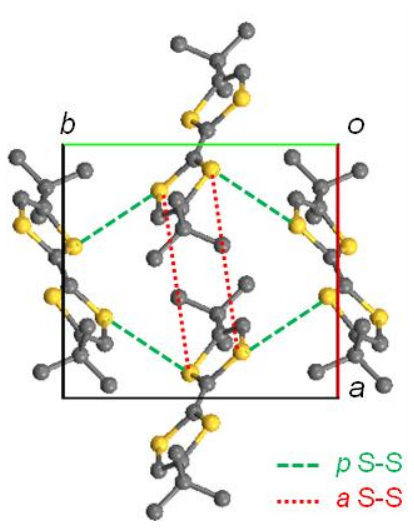

(c)

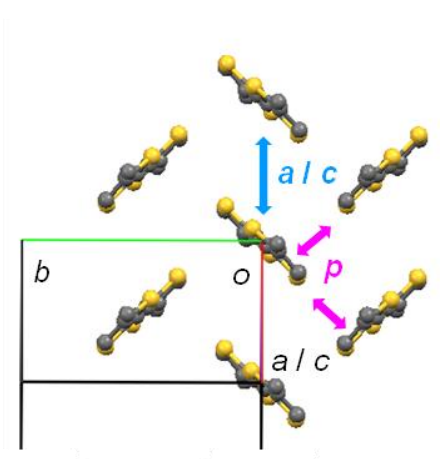


Figure 3. Crystal structure of 2. (a) Top and side views of the molecular structure; (b) view perpendicular to the molecular plane (hydrogen atoms are not shown); and (c) projection along the molecular long axis (tert-butyl groups are not shown). Anisotropic displacement ellipsoids are drawn at the $50 \%$ probability level.

(a)

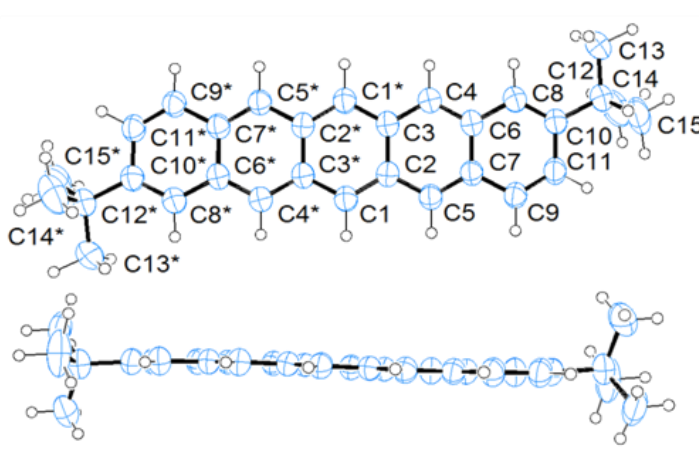

(b)

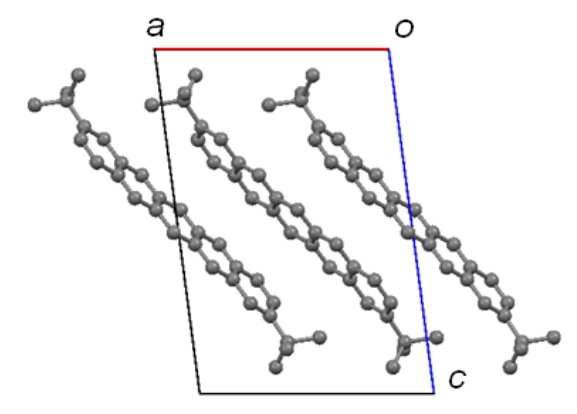

(c)

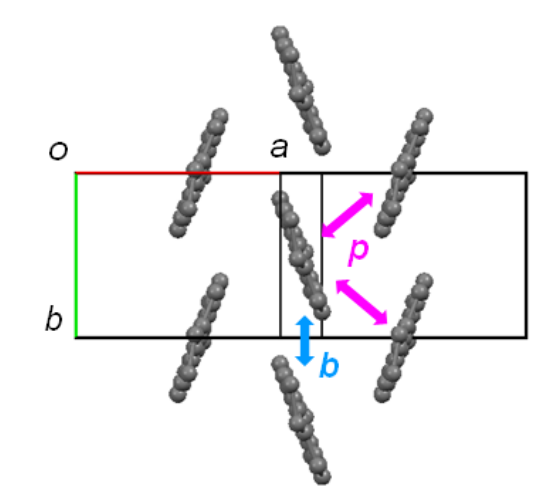

Compounds 1 and $\mathbf{2}$ have herringbone-type molecular packings, where the stacking directions are $a$ for 1 and $b$ for 2 , and the dihedral angles are $89^{\circ}$ and $42^{\circ}$, respectively. In order to discuss the intermolecular interactions, transfer integrals $(t)$ are shown in Table 3 [31] together with the slip distances along the molecular long axis $(D)$ and the short sulfur-sulfur distances $(\mathrm{S}-\mathrm{S})$. The transfer integrals are as a whole small in spite of the herringbone-like packing. In particular, the intracolumnar (a) and intercolumnar $(c)$ interactions in $\mathbf{1}$ are very small owing to the large slip distances along the molecular long axes $(D=8.1$ and $5.0 \AA$, respectively). The two-dimensional interaction is, however, maintained by the diagonal interaction $(p)$, though this transfer integral is relatively small. This is due to the large dihedral angle of $89^{\circ}$, which is usually disadvantageous in the herringbone structures [32]. Short S-S distances exist in this direction.

Table 3. Intermolecular transfer integrals and geometric parameters.

\begin{tabular}{ccccccc}
\hline $\mathbf{1}$ & $\boldsymbol{t}(\mathbf{m e V})$ & $\boldsymbol{D}(\AA)$ & $\mathbf{S}-\mathbf{S}(\AA)$ & $\mathbf{2}$ & $\boldsymbol{t}(\mathbf{m e V})$ & $\boldsymbol{D}(\mathbf{\AA})$ \\
\hline$a$ & 1 & 8.1 & 6.59 & $b$ & -23 & 1.2 \\
$c$ & -5 & 5.0 & 5.73 & $p$ & -1 & - \\
$p$ & -11 & - & 3.70 & & & \\
\hline
\end{tabular}

The dihedral angle of 2 is small $\left(42^{\circ}\right)$, and closes to $53^{\circ}$ of the unsubstituted pentacene [33]. The predominant interaction is, however, the intracolumnar interaction $(b)$, which results in relatively one-dimensional transport. This is because $D$ is small for $b(1.2 \AA)$, but as large as $4 \AA$ for $p$. This 
reminds us of the previously reported alkyl-substituted BEDT-TTF molecules [34], where large $D$ destroys the intermolecular networks.

In the herringbone structure, the bandwidths are estimated to be $4\left|t_{\mathrm{a}}\right|+4\left|t_{\mathrm{c}}\right|+8\left|t_{\mathrm{p}}\right|=112 \mathrm{meV}$ for $\mathbf{1}$ and $4\left|t_{\mathrm{b}}\right|+8\left|t_{\mathrm{p}}\right|=100 \mathrm{meV}$ for 2 [32]. These values are smaller than the bandwidth of TTF stacks in (TTF)(TCNQ) $(0.48 \mathrm{eV})$ [35] and the unsubstituted pentacene $(200 \mathrm{meV})$, on account of the steric hindrance of the tert-butyl groups, and the resulting relatively large intermolecular distances.

\subsection{Thin-Film Properties}

Atomic force microscopy (AFM) images of thin films deposited on hexamethylenedisilazane (HMDS)-treated $\mathrm{SiO}_{2} / \mathrm{Si}$ substrates are shown in Figure 4. A thin film of $\mathbf{1}$ consists of block-like grains with large voids and roughness. Plate-like grains as large as more than $2 \mu \mathrm{m}$ are formed for 2 . The grain size increases with increasing the substrate temperatures. In contrast, $\mathbf{3}$ forms many dense small grains, and the substrate is well covered.

Figure 4. Atomic force microscopy (AFM) images and X-ray diffraction (XRD) patterns of the thin films deposited on hexamethylenedisilazane (HMDS)-treated $\mathrm{SiO}_{2}:$ (a) and (d) for $\mathbf{1}$; (b) and (e) for 2 at $T_{\text {sub }}=60^{\circ} \mathrm{C}$ and (c) and (f) for 3 .

(a)

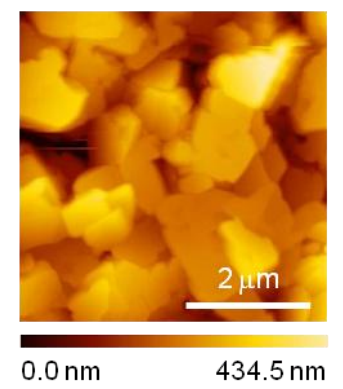

(d)

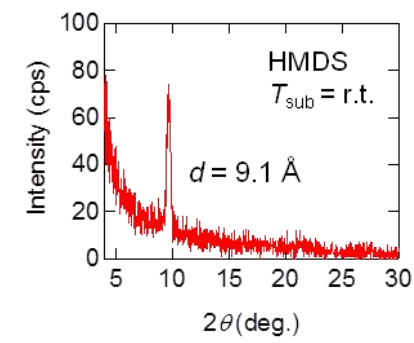

(b)

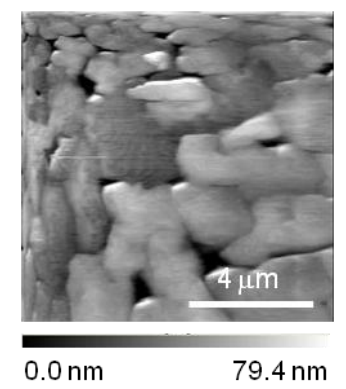

(e)

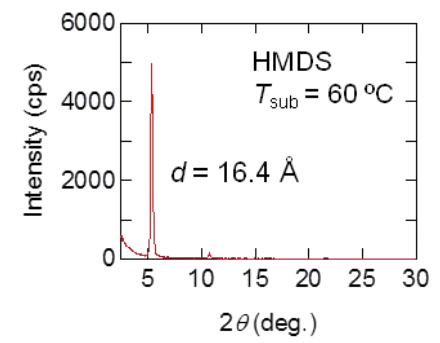

(c)

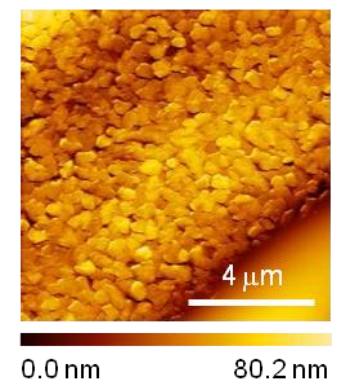

(f)

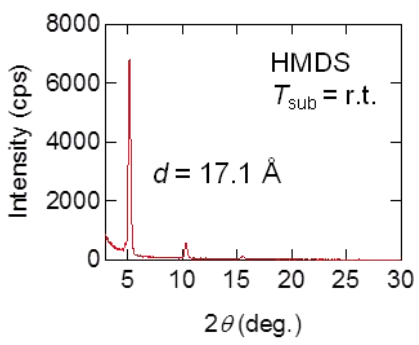

The thin films of 1, 2 and $\mathbf{3}$ show clear X-ray diffraction (XRD) peaks (Figure 4). In the thin films of 2 and 3, the large peaks are observed, indicating formation of lamellar ordering and good crystallinity. The $d$ values are $9.1 \AA$ and $16.4 \AA$ for $\mathbf{1}$ and 2, respectively, in good agreement with the crystallographic $c$ axes (Table 1). The thin film of $\mathbf{3}$ shows the $d$ value of $17.1 \AA$, which is shorter than the molecular length $(21.9 \AA)$, indicating that the molecules are tilted by $52^{\circ}$ from the surface normal. 


\subsection{Transistor Propzerties}

OFETs with top-contact Au electrodes are fabricated by vacuum deposition of $\mathbf{1}, \mathbf{2}$, and $\mathbf{3}$ on the bare and HMDS-treated $\mathrm{SiO}_{2} / \mathrm{Si}$ substrates. The OFET characteristics are measured in air (Table 4). Compound 1 does not show transistor properties. Compound $\mathbf{2}$ shows increasing performance with increasing the deposition temperature, and exhibits a mobility of $2.8 \times 10^{-3} \mathrm{~cm}^{2} \mathrm{~V}^{-1} \mathrm{~s}^{-1}$ for a thin film deposited at $60{ }^{\circ} \mathrm{C}$ (Figure 5a,b). This is due to the increasing grain size and the decreasing number of grain boundaries [36,37], as observed in AFM and XRD. After 30 days, the device shows reduced carrier mobility by two orders of magnitude, though the unsubstituted pentacene does not show transistor properties at all after this period.

Table 4. Transistor characteristics of 2 and 3.

\begin{tabular}{|c|c|c|c|c|c|}
\hline Compounds & SAMs & & $\mu\left(\mathrm{cm}^{2} \mathrm{~V}^{-1} \mathrm{~s}^{-1}\right)$ & $V_{\text {th }}(\mathbf{V})$ & $I_{\mathrm{on}} / I_{\mathrm{off}}$ \\
\hline \multirow{4}{*}{2} & \multirow{4}{*}{ HMDS } & r.t. & $2.5 \times 10^{-4}$ & -36 & $1 \times 10^{3}$ \\
\hline & & $40^{\circ} \mathrm{C}$ & $2.9 \times 10^{-4}$ & -22 & $2 \times 10^{2}$ \\
\hline & & $60^{\circ} \mathrm{C}$ & $2.8 \times 10^{-3}$ & -44 & $2 \times 10^{3}$ \\
\hline & & $\begin{array}{l}\text { after } 30 \\
\text { days }\end{array}$ & $1.3 \times 10^{-5}$ & -20 & 26 \\
\hline \multirow{2}{*}{3} & bare & r.t. & $6.3 \times 10^{-3}$ & -17 & $2 \times 10^{4}$ \\
\hline & HMDS & r.t. & $3.5 \times 10^{-3}$ & -17 & $1 \times 10^{4}$ \\
\hline \multirow{2}{*}{$4 \mathrm{~T}$} & bare & r.t. & $3.5 \times 10^{-3}$ & -20 & $6 \times 10^{3}$ \\
\hline & HMDS & r.t. & $7.8 \times 10^{-3}$ & -13 & $6 \times 10^{4}$ \\
\hline
\end{tabular}

Figure 5. (a) Transfer and (b) output characteristics of 2, for devices fabricated at $T_{\text {sub }}=60{ }^{\circ} \mathrm{C}$ with top-contact $\mathrm{Au}$ electrodes. The dotted curves are characteristics after 30 days. (c) Transfer and (d) output characteristics of $\mathbf{3}$, for devices fabricated at room temperature.

(a)

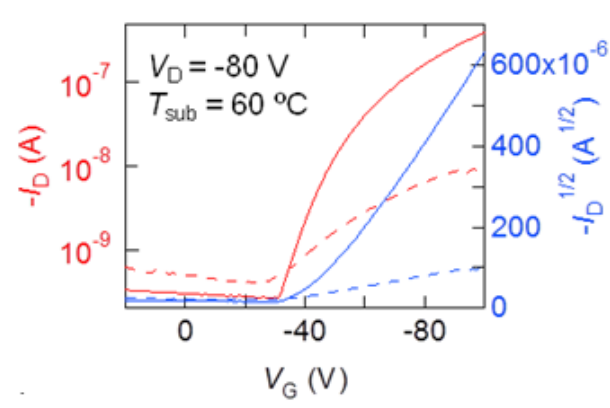

(c)

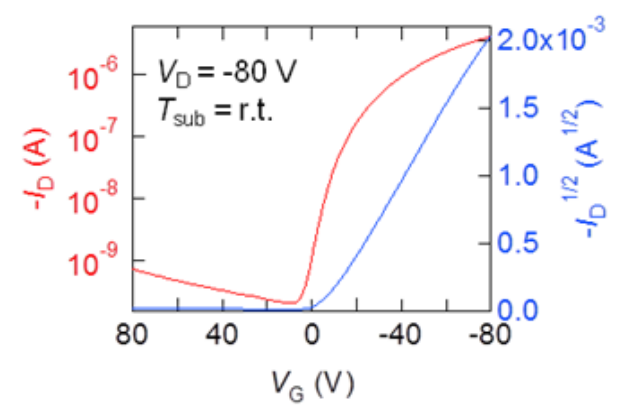

(b)

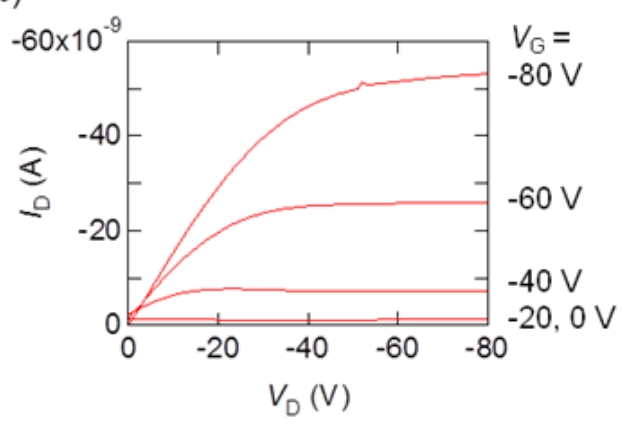

(d)

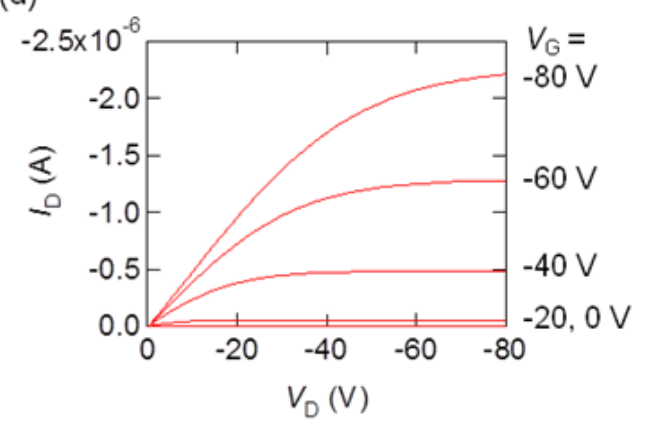


Compound 3 shows comparable mobility to similarly fabricated devices of the unsubstituted $4 \mathrm{~T}$ (Figure 5c,d). Interestingly, the device fabricated on the bare substrate has shown higher mobility than that of the HMDS-treated substrates, suggesting that the tert-butyl substitution plays a role of self-assembled monolayers (SAMs). It is a merit of $\mathbf{3}$ that this material can be used without SAMs-treatment.

\subsection{Charge-Transfer Salt}

Since $\mathbf{1}$ is a strong electron donor, the charge-transfer salts are prepared. Slow evaporation of an acetonitrile solution of $\mathbf{1}$ and tetracyanoquinodimethane (TCNQ) has given black needles of (1)(TCNQ). The crystallographic data are listed in Table 5, and the crystal structure is depicted in Figure 6. The crystal belongs to the space group $P 4_{2} / m b c$, and each half of $\mathbf{1}$ and TCNQ is crystallographically independent. A unit cell contains respective four molecules of $\mathbf{1}$ and TCNQ, and the composition is $1: 1$. Both molecules are located on the $2 / m$ sites, and form segregated stacks. This crystal contains only the $E$-isomer of $\mathbf{1}$. The TTF and TCNQ molecules are located on the mirror planes $(z=0)$. There is a $4_{2}$-screw axis parallel to the TTF stack, but is only the two-fold axis along the TCNQ stack. Among charge-transfer salts of TTF derivatives, halides of TTF and $o$-dimethyl-TTF have tetragonal symmetry [38,39]. In these halides, however, the halogen ions are located on the four-fold axis, and the TTF molecules form regular parallel stacks. On the contrary, in the present complex, the TTF stack is located on the $4_{2}$-screw axis. The TTF molecules are disordered to two positions with occupancy $69 \%$ for the majority molecule (M1) and $31 \%$ for the minority molecule (M2). The M1 and M2 molecules are arranged in a staggered manner as the two molecules depicted in Figure 6(b), but share the common tert-butyl parts. The $4_{2}$-screw axis generates perpendicular molecules M1' and M2' at the $z=1 / 2$ position (Figure $6(\mathrm{c})$ ). Here, the $z=1 / 2$ position defines the next molecule in the stack, and $c / 2=3.417 \AA$ corresponds to the interplanar distance. The sulfur atoms of the M1' molecule are located just on the top of the sulfur atoms of the M1 molecule, so that M1-M1' arrangement is an eclipsed conformation. M2-M2' arrangement is similarly an eclipsed stack, but M1-M2' and M1'-M2 are staggered. Since there is no disorder on the tert-butyl groups, the M1 and M2 molecules always appear at $z=0$, and M1' and M2' are only at $z=1 / 2$. On the basis of the molecular orbital calculation [31], the eclipsed arrangements afford large transfer integrals (M1-M1': 323 meV and M2-M2': $315 \mathrm{meV}$ ), whereas the staggered arrangements afford small transfers (M1-M2': $103 \mathrm{meV}$ and M1'-M2: $96 \mathrm{meV}$ ). The TCNQ molecules form an ordered regular stack of slightly rotated molecules, and the transfer integral is only one $(121 \mathrm{meV})$. There are no meaningful intercolumnar transfer integrals, and the electronic structure is highly one-dimensional. This is due to the steric effect of the tert-butyl groups, which reminds us conducting nanowires surrounded by supramolecular insulating networks [40]. It is noteworthy that the intercolumnar directions are completely isotropic owing to the tetragonal symmetry. 
Table 5. Crystallographic data for (1) tetracyanoquinodimethane (TCNQ).

\begin{tabular}{cc}
\hline & $(\mathbf{1})(\mathbf{T C N Q})$ \\
\hline Empirical formula & $\mathrm{C}_{26} \mathrm{H}_{24} \mathrm{~S}_{4} \mathrm{~N}_{4}$ \\
Formula weight & 520.74 \\
Temperature (K) & 273 \\
Crystal system & tetragonal \\
Space group & $P 4_{2} / m b c$ \\
$a(\AA)$ & $19.7657(7)$ \\
$c(\AA)$ & $6.8345(3)$ \\
$V\left(\AA^{3}\right)$ & $2670.1(2)$ \\
$Z$ & 4 \\
$D_{\text {calc }}\left(\mathrm{g} / \mathrm{cm}^{3}\right)$ & 1.295 \\
Reflections $($ unique $)$ & $29583(1335)$ \\
$R_{1}$ & 0.0938 \\
$R_{\mathrm{w}}$ & 0.2868 \\
$\mathrm{GOF}$ & 1.08 \\
\hline
\end{tabular}

Figure 6. Crystal structure of (1)(TCNQ). (a) Projection along the $c$ axis; and the molecules at (b) $z=0$; and (c) $z=1 / 2$.

(a)

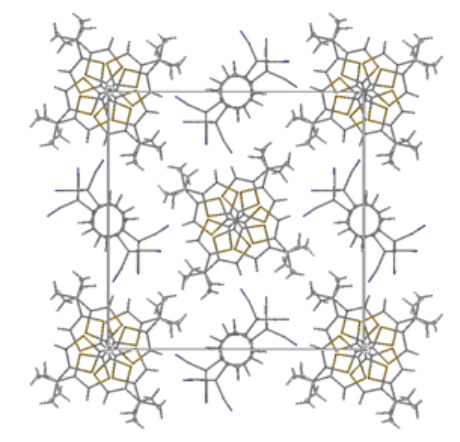

(b)

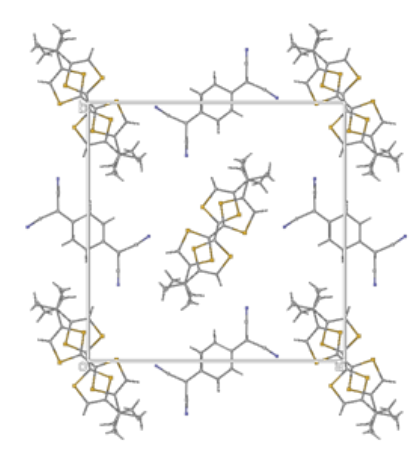

(c)

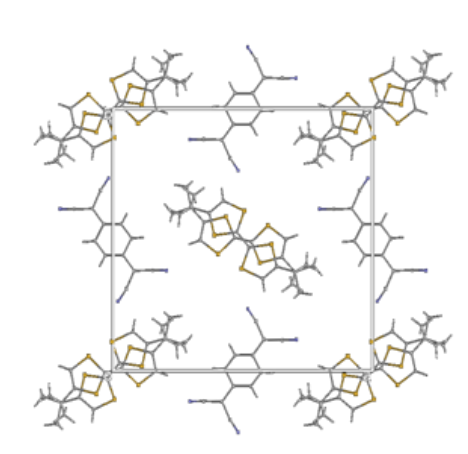

The infrared (IR) spectrum shows the CN stretching at $2189 \mathrm{~cm}^{-1}$, from which the degree of charge transfer is estimated to be 0.86 [41]. This salt shows room-temperature conductivity of $7 \mathrm{~S} \mathrm{~cm}^{-1}$, and activated temperature dependence with the activation energy of $0.1 \mathrm{eV}$.

The X-ray photograph (Figure 7) shows broad satellites at the $(1 / 3) c^{*}$ positions. The three-fold periodicity is agreeable to the 2:1 disorder, and, we suppose, a stack is composed of such molecular arrangement as -M1-M1'-M2-M1"-M1-M2'-. Note that the dashed molecules have to appear alternately, and the ratio of M1 and M2 is 2:1. The eclipsed arrangements (M1-M1' and M2-M2') appear twice, and other four are staggered arrangements. This six-fold periodicity is the reason that all our attempts are unsuccessful to solve the crystal structure without disorder in a lower symmetry. We also suspect that there is no order of the M2 positions between the adjacent columns. If we can approximate the IR result to be $2 / 3$ charge transfer, namely $\left(\mathrm{TTF}^{2 / 3+}\right)\left(\mathrm{TCNQ}^{2 / 3-}\right)$, we can also imagine charge order such as $\mathrm{M}^{+}-\mathrm{M} 1^{+}-\mathrm{M} 2^{0}$, though charge disproportionation is not obvious from the bond lengths. This charge transfer degree is slightly larger than 0.59 of (TTF)(TCNQ) [42], and approximately the same as (TTF) $\mathrm{Cl}_{0.77}[38]$. 
Figure 7. X-ray photograph of (1)(TCNQ) approximately along the $c^{*}$-axis at $273 \mathrm{~K}$.

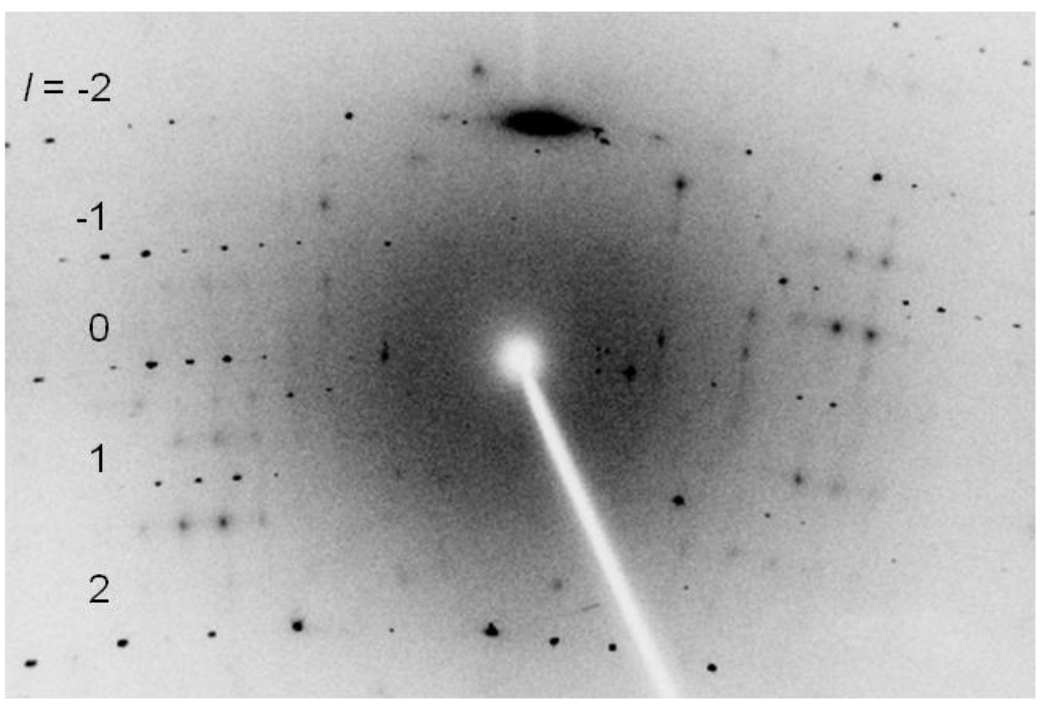

\section{Experimental Section}

\subsection{Synthesis}

Column chromatography was carried out on silica gel (Wako Wakogel C-200). For thin-layer chromatography (TLC) analysis, Merck pre-coated plates (silica gel $60 \mathrm{~F} 254,0.25 \mathrm{~mm}$ ) were used. The ${ }^{1} \mathrm{H}-\mathrm{NMR}$ (300 MHz) spectra were recorded using a JEOL JNM-AL300 spectrometer. Chemical shifts were given in $\delta$ values (ppm) using TMS as the internal standard. Mass spectra were taken on a Shimadzu GC-MS-QP-5000 mass spectrometer. The IR spectra were obtained on a Shimadzu FTIR-8400S spectrometer.

S-(3,3-Dimethyl-2-oxobutyl)-O-isopropylcarbonodithioate (4). 1-chloro-3,3-dimethylbutan-2-one (1.35 g, $10 \mathrm{mmol})$ was added dropwise to a solution of potassium isopropylxanthate $(1.92 \mathrm{~g}, 11 \mathrm{mmol})$ in acetone $(20 \mathrm{~mL})$, and the reaction mixture was stirred for $1 \mathrm{~h}$. The obtained white suspension was filtered, and the filtrate was evaporated to give a pale yellow oil 4 (2.30 g, $9.81 \mathrm{mmol}$, yield 98\%). MS (EI) $m / z 234\left[\mathrm{M}^{+}\right] ;{ }^{1} \mathrm{H}-\mathrm{NMR}\left(300 \mathrm{MHz}, \mathrm{CDCl}_{3}\right) \delta 5.73(\mathrm{~m}, 1 \mathrm{H}), 4.26(\mathrm{~s}, 2 \mathrm{H}), 1.40(\mathrm{~d}, 6 \mathrm{H}), 1.25(\mathrm{~s}, 9 \mathrm{H})$.

4-tert-Butyl-1,3-dithiol-2-one (5). Compound 4 (4.37 g, $18.6 \mathrm{mmol})$ was added dropwise to ice-cooled sulfuric acid $(20 \mathrm{~mL})$, and after $2 \mathrm{~h}$ stirring, the resulting mixture was poured onto ice $(40 \mathrm{~g})$. The product was extracted with diethyl ether, washed with water, a saturated aqueous solution of sodium hydrogen carbonate and brine, and dried over magnesium sulfate. After evaporation, the product was purified by column chromatography (ethyl acetate:hexane $=1: 2, R_{\mathrm{f}}=0.8$ ), to give a yellow oil 5 (2.65 g, $15.2 \mathrm{mmol}$, yield 82\%). MS (EI) m/z $174\left[\mathrm{M}^{+}\right] ;{ }^{1} \mathrm{H}-\mathrm{NMR}\left(300 \mathrm{MHz}, \mathrm{CDCl}_{3}\right)$ $\delta 6.30(\mathrm{~s}, 1 \mathrm{H}), 1.30(\mathrm{~s}, 9 \mathrm{H})$.

4,4'-Di(tert-butyl)tetrathiafulvalene (1). Distilled triethylphosphite (3.5 mL, $20.8 \mathrm{mmol})$ was added to a solution of 5 (1.49 g, $8.5 \mathrm{mmol})$ in dry toluene $(5 \mathrm{~mL})$ under $\mathrm{N}_{2}$ atmosphere, and refluxed for $17 \mathrm{~h}$. Distilled triethylphosphite $(3.0 \mathrm{~mL}, 17.9 \mathrm{mmol})$ was further added, and refluxed for $5 \mathrm{~h}$. After the triethylphosphite was removed by distillation under vacuum, the product was purified by column chromatography (dichloromethane:hexane $\left.=1: 1, R_{\mathrm{f}}=0.7\right)$, to give an orange solid $\mathbf{1}(0.86 \mathrm{~g}$, 
$2.72 \mathrm{mmol}$, yield 65\%). The $E$-isomer of 1 was isolated by repeated recrystallization from ethanol. m.p. $172{ }^{\circ} \mathrm{C}$; MS (EI) m/z $316\left[\mathrm{M}^{+}\right] ;{ }^{1} \mathrm{H}-\mathrm{NMR}\left(300 \mathrm{MHz}, \mathrm{CDCl}_{3}\right) \delta 5.85$ (s, 2H), 1.24 (s, 18H).

4-tert-Butyl-1,2-bis(dibromomethyl)benzene (6). $N$-bromosuccinimide (37.4 g, $210 \mathrm{mmol}$ ) was added to a solution of 4-tert-butyl-1,2-dimethylbenzene $(8.16 \mathrm{~g}, 50.3 \mathrm{mmol})$ in tetrachloromethane $(100 \mathrm{~mL})$ under $\mathrm{N}_{2}$ atmosphere. The mixture was stirred for $30 \mathrm{~min}$, and refluxed for $24 \mathrm{~h}$. The orange suspension was filtered, and the residue was washed with diethyl ether. The resulting filtrate was concentrated under reduced pressure. The product was extracted with dichloromethane and washed with water, a saturated aqueous solution of sodium sulfite and brine. The organic layer was dried over magnesium sulfate and concentrated under reduced pressure. The product was recrystallized from hexane, to give a white solid $6\left(19.34 \mathrm{~g}, 40.5 \mathrm{mmol}\right.$, yield 81\%). MS (EI) $\mathrm{m} / \mathrm{z} 478\left[\mathrm{M}^{+}\right]$.

4-tert-Butylphthalaldehyde (7). $50 \%$ aqueous dimethylamine $(30 \mathrm{~mL})$ was added to a solution of $6(2.73 \mathrm{~g}, 10.7 \mathrm{mmol})$ in toluene $(20 \mathrm{~mL})$ under $\mathrm{N}_{2}$ atmosphere, stirred for $24 \mathrm{~h}$, and refluxed for $48 \mathrm{~h}$. The reaction mixture was extracted with ethyl acetate, and washed with $10 \%$ aqueous hydrochloric acid, water and brine. The organic layer was dried over magnesium sulfate and concentrated under reduced pressure. The product was purified by column chromatography (ethyl acetate:hexane $=2: 1$, $\left.R_{\mathrm{f}}=0.7\right)$, to give a red oil $7\left(1.30 \mathrm{~g}, 6.83 \mathrm{mmol}\right.$, yield 64\%). MS (EI) $\mathrm{m} / \mathrm{z} 190\left[\mathrm{M}^{+}\right]$; ${ }^{1} \mathrm{H}-\mathrm{NMR}$ $\left(300 \mathrm{MHz}, \mathrm{CDCl}_{3}\right) \delta 10.59(\mathrm{~s}, 1 \mathrm{H}), 10.49(\mathrm{~s}, 1 \mathrm{H}), 7.99(\mathrm{~d}, 1 \mathrm{H}), 7.92(\mathrm{~d}, 1 \mathrm{H}), 7.78(\mathrm{dd}, 1 \mathrm{H})$.

2,9-Di(tert-butyl)pentacene-6,13-dione (8). 15\% potassium hydroxide aqueous solution $(50 \mathrm{~mL})$ was added dropwise to a mixture of $7(4.74 \mathrm{~g}, 25.0 \mathrm{mmol})$ and 1,4-cyclohexanedione $(1.34 \mathrm{~g}, 12.5 \mathrm{mmol})$. After stirring for $2 \mathrm{~h}$, the reaction mixture was poured into water $(120 \mathrm{~mL})$ for quenching. The resulting solid was filtered and washed with water, followed by ethanol, to give a yellow solid $\mathbf{8}$ ( $3.71 \mathrm{~g}, 8.82 \mathrm{mmol}, 71 \%$ ). The $E$-isomer of $\mathbf{8}$ was isolated by repeated recrystallization from ethyl acetate. m.p. $290{ }^{\circ} \mathrm{C} ; \mathrm{MS}(\mathrm{EI}) \mathrm{m} / \mathrm{z} 420\left[\mathrm{M}^{+}\right]$.

2,9-Di(tert-butyl)pentacene (2). Lithium aluminium hydride $(0.2 \mathrm{~g}, 5.3 \mathrm{mmol})$ was added to a solution of $8(0.2 \mathrm{~g}, 0.48 \mathrm{mmol})$ in dry THF $(15 \mathrm{~mL})$ under $\mathrm{N}_{2}$ atmosphere and refluxed for $12 \mathrm{~h} .6 \mathrm{M}$ aqueous hydrochloric acid $(6 \mathrm{~mL})$ was added to the reaction mixture under cooling with ice and refluxed for $1 \mathrm{~h}$. The mixture was cooled to room temperature and water was added. The residue was filtered and washed with water, followed by ethanol. The product was purified by sublimation $\left(250{ }^{\circ} \mathrm{C}\right)$, to give a violet solid (0.14 g, $0.35 \mathrm{mmol}, 73 \%)$. MS (EI) $\mathrm{m} / \mathrm{z} 390\left[\mathrm{M}^{+}\right]$.

2-Bromo-5-tert-butylthiophene (12). A solution of thiophene (4.60 g, $54.8 \mathrm{mmol})$ and tert-butyl chloride $(5.13 \mathrm{~g}, 55.5 \mathrm{mmol})$ in dry dichloromethane $(10 \mathrm{~mL})$ was added dropwise to a mixture of aluminium chloride $(7.30 \mathrm{~g}, 54.8 \mathrm{mmol})$ in dry dichloromethane $(20 \mathrm{~mL})$ at $-70{ }^{\circ} \mathrm{C}$ under $\mathrm{N}_{2}$ atmosphere and stirred for $1 \mathrm{~h}$ at this temperature before stirred for $40 \mathrm{~h}$ at room temperature. The mixture was poured onto ice, and a saturated aqueous solution of sodium hydrogen carbonate was added for quenching. The organic layer was washed with water and brine, dried over magnesium sulfate and concentrated under reduced pressure. The obtained brown oil $\mathbf{1 1}$ was dissolved in dichloromethane $(20 \mathrm{~mL}) . \mathrm{N}$-bromosuccinimide $(9.75 \mathrm{~g}, 54.8 \mathrm{mmol})$ was slowly added, and stirred for $1 \mathrm{~h}$. The mixture was washed with water and brine, dried over magnesium sulfate, and concentrated under reduced pressure. The product was distilled under vacuum, to give a yellow oil 12 (5.41 g, 
$24.7 \mathrm{mmol}$, yield 45\%). MS (EI) m/z $219\left[\mathrm{M}^{+}\right],{ }^{1} \mathrm{H}-\mathrm{NMR}\left(300 \mathrm{MHz}, \mathrm{CDCl}_{3}\right) \delta 1.35(\mathrm{~s}, 9 \mathrm{H}), 6.57(\mathrm{~d}$, $J=3.6 \mathrm{~Hz}, 1 \mathrm{H}), 6.84(\mathrm{~d}, J=3.6 \mathrm{~Hz}, 1 \mathrm{H})$.

$\alpha, \omega$-Di(tert-butyl)quaterthiophene (3). A solution of $n$-butyl lithium $(6.90 \mathrm{~mL}, 11.0 \mathrm{mmol})$ in 1.6 $\mathrm{M}$ hexane was dropwise added to a solution of thiophene $(0.84 \mathrm{~g}, 10.0 \mathrm{mmol})$ in dry diethyl ether $(20 \mathrm{~mL})$ at $-40{ }^{\circ} \mathrm{C}$ under $\mathrm{N}_{2}$ atmosphere, and stirred for $2 \mathrm{~h}$. After tributyltin chloride $(3.26 \mathrm{~g}, 10 \mathrm{mmol})$ was dropwise added, the mixture was refluxed overnight. The reaction mixture was extracted with dichloromethane, washed with water, and dried over magnesium sulfate. Concentration under reduced pressure gives a yellow oil (3.70 g, $9.9 \mathrm{mmol})$. The obtained oil $(1.86 \mathrm{~g}, 5.0 \mathrm{mmol})$ was dissolved in dry toluene $(20 \mathrm{~mL})$, to which $12(1.10 \mathrm{~g}, 5.0 \mathrm{mmol})$ and tetrakis(triphenylphosphine)paradium(0) $(0.29 \mathrm{~g}, 0.25 \mathrm{mmol})$ was added, and refluxed overnight. The reaction mixture was quenched by adding a saturated aqueous solution of ammonium chloride, extracted with diethyl ether, washed with water, dried over magnesium sulfate, and concentrated under reduced pressure. The obtained brown oil was distilled under vacuum, to give a colorless oil 13 (0.89 g, $4.0 \mathrm{mmol}$, yield 80\%).

A solution of $n$-butyl lithium $(1.50 \mathrm{~mL}, 2.40 \mathrm{mmol})$ in $1.6 \mathrm{M}$ hexane was dropwise added to a solution of diisopropylamine $(0.22 \mathrm{~g}, 2.16 \mathrm{mmol})$ in dry THF $(5 \mathrm{~mL})$ at $-78{ }^{\circ} \mathrm{C}$ under $\mathrm{N}_{2}$ atmosphere. A solution of $13(0.48 \mathrm{~g}, 2.16 \mathrm{mmol})$ in dry THF $(3 \mathrm{~mL})$ was dropwise added, and stirred for $30 \mathrm{~min}$. A mixture of anhydrous copper(II) chloride $(0.29 \mathrm{~g}, 2.16 \mathrm{mmol})$ in DMF (3 mL) was added and stirred for another $1 \mathrm{~h}$. The reaction was quenched by $3 \%$ aqueous hydrochloric acid, extracted with dichloromethane, washed with water, dried over magnesium sulfate, and concentrated under reduced pressure. The product was purified by column chromatography (dichloromethane:hexane $=1: 1$ ), and recrystallization from ethanol gives a yellow solid $3(0.23 \mathrm{~g}, 0.52 \mathrm{mmol}$, yield $49 \%)$. m.p. $222{ }^{\circ} \mathrm{C}$; MS (EI) $m / z, 442\left[\mathrm{M}^{+}\right] ;{ }^{1} \mathrm{H}-\mathrm{NMR}\left(300 \mathrm{MHz}, \mathrm{CDCl}_{3}\right) \delta 1.23(\mathrm{~s}, 18 \mathrm{H}), 6.74(\mathrm{~d}, J=3.6 \mathrm{~Hz}, 2 \mathrm{H}), 6.99$ $(\mathrm{d}, J=3.6 \mathrm{~Hz}, 2 \mathrm{H}), 7.00(\mathrm{~d}, J=3.9 \mathrm{~Hz}, 2 \mathrm{H}), 7.03(\mathrm{~d}, J=3.6 \mathrm{~Hz}, 2 \mathrm{H})$.

\subsection{Redox Properties}

Cyclic voltammograms were measured on an ALS CHI-700C electrochemical analyzer in $0.1 \mathrm{M}$ tetrabutylammonium hexafluorophosphate $\left(n-\mathrm{Bu}_{4} \mathrm{~N} \cdot \mathrm{PF}_{6}\right)$ solutions of benzonitrile at a scan rate of $100 \mathrm{mV} / \mathrm{s}$. The reference electrode was $\mathrm{Ag} / \mathrm{AgNO}_{3}$ with glassy carbon working electrode and a $\mathrm{Pt}$ supporting electrode. All the measured potentials were normalized with the ferrocene/ferrocenium redox potential of $E_{1 / 2}=0.40 \mathrm{~V} v s$. SCE and $-4.8 \mathrm{eV}$ to vacuum.

\subsection{Photophysical Properties}

UV-vis spectra in chloroform were measured on a Hitachi U-2800 UV-vis double beam spectrophotometer at room temperature using a quartz cuvette with a path length of $1 \mathrm{~cm}$. Optical bandgaps (HOMO-LUMO gaps) were calculated from the edge of the visible-absorption bands.

\subsection{Single Crystal Structures and Intermolecular Overlap Integral Calculations}

The reflection data were collected on a Rigaku R-AXIS RAPID-II diffractometer using $\mathrm{CuK} \alpha$ radiation $(\lambda=1.54187 \AA$ ) monochromated by confocal mirror (Rigaku VariMax) at $173 \mathrm{~K}$. The temperature was controlled by a Rigaku cryostat system. Empirical absorption correction was applied 
with the ABSCOR program. The structures were solved by the direct method using the SHELX-97 [43] and SIR-92 [44], and refined by full-matrix least squares by applying anisotropic temperature factors for all non-hydrogen atoms. The hydrogen atoms were generated geometrically and were refined with the riding model for $\mathbf{1}$, and were determined from the experimental data for $\mathbf{2}$. The intermolecular transfer integrals $t_{\mathrm{i}}$ between the HOMOs were calculated on the basis of the extended Hückel molecular orbital calculation by using the same atomic parameters [31].

\subsection{Device Fabrication}

Transistors were fabricated onto n-doped $\mathrm{Si}$ substrates with a thermally grown $\mathrm{SiO}_{2}$ dielectric layer $(300 \mathrm{~nm})$ treated with HMDS. The organic semiconductors were, after purification by sublimation, vacuum evaporated on the substrates with a thickness of $50 \mathrm{~nm}$. AFM images were obtained with a Seiko Instruments SPA-300 and SPI3800 probe system by using an $\mathrm{Si}_{3} \mathrm{~N}_{4}$ cantilever. XRD measurements of the thin films were carried out by Phillips X'Pert-MPD-OEC PW3050 with a monochromated $\mathrm{CuK} \alpha$ radiation $(\lambda=1.542512 \AA)$.

The top-contact electrodes were patterned by thermal deposition of $\mathrm{Au}(50 \mathrm{~nm})$ using a shadow mask; the channel length and width were $100 \mu \mathrm{m}$ and $1000 \mu \mathrm{m}$, respectively. The transistor characteristics were measured under ambient conditions by using a Keithley 4200 semiconductor parameter analyzer, and the mobility was evaluated from the transconductance in the saturated region.

\subsection{Conductivity Measurement}

Conductivity of (1)(TCNQ) was measured by the four-probe method applying a low-frequency ac current along the crystallographic $c$-axis.

\section{Conclusions}

TTF, pentacene, and 4T with bulky tert-butyl groups are prepared. Although the crystal density is remarkably reduced, the crystals have relatively simple herringbone structures. The tert-butyl groups largely destroy the transistor properties of TTF and pentacene, but the 4T derivative shows transistor performance comparable to the parent 4T, and interestingly, the performance on bare $\mathrm{SiO}_{2}$ is $\mathrm{improved}_{\text {. }}$ In the TCNQ complex of the tert-butyl TTF, each column is separated by the tert-butyl groups to construct a highly one-dimensional system.

\section{Acknowledgments}

This work was partly supported by a Grant-in Aid for Scientific Research (B) (No. 23350061) from the Ministry of Education, Culture, Sports, Science, and Technology of Japan. We would like to express sincere gratitude to H. Iida, Center for Advanced Materials Analysis, Tokyo Institute of Technology, for X-ray diffraction measurements.

\section{References}

1. Mori, T. Organic charge-transfer salts and the component molecules in organic transistors. Chem. Lett. 2011, 40, 428-434. 
2. Kanno, M.; Bando, Y.; Shirahata, T.; Inoue, J.; Wada, H.; Mori, T. Stabilization of organic field-effect transistors in hexamethylenetetrathiafulvalene derivatives substituted by bulky alkyl groups. J. Mater. Chem. 2009, 19, 6548-6555.

3. Inoue, J.; Kanno, M.; Ashizawa, M.; Seo, C.; Tanioka, A.; Mori, T. Organic transistors based on octamethylenetetrathiafulvalenes. Chem. Lett. 2010, 39, 538-540.

4. Nagakubo, J.; Ashizawa, M.; Kawamoto, T.; Tanioka, A.; Mori, T. Stabilization of organic field-effect transistors by tert-butyl groups in dibenzotetrathiafulvalene derivatives. Phys. Chem. Chem. Phys. 2011, 13, 14370-14377.

5. Takahashi, Y.; Hasegawa, T.; Horiuchi, S.; Kumai, R.; Tokura, Y.; Saito, G. High mobility organic field-effect transistor based on hexamethylenetetrathiafulvalene with organic metal electrodes. Chem. Mater. 2007, 19, 6382-6384.

6. Mas-Torrent, M.; Hadley, P.; Bromley, S.T.; Crivillers, N.; Rovira, C. Single-crystal organic field-effect transistors based on dibenzo-tetrathiafulvalene. Appl. Phys. Lett. 2005, 86, 012110:1-012110:3.

7. Shibata, K.; Ishikawa, K.; Takezoe, H.; Wada, H.; Mori, T. Contact resistance of dibenzotetrathiafulvalene-based organic transistors with metal and organic electrodes. Appl. Phys. Lett. 2008, 92, 023305:1-023305:3.

8. Yamada, T.; Hasegawa, T.; Hiraoka, M.; Matsui, H.; Tokura, Y.; Saito, G. Control of film morphology and its effects on subthreshold characteristics in dibenzotetrathiafulvalene organic thin-film transistors. Appl. Phys. Lett. 2008, 92, 233306:1-233306:3.

9. Dhindsa, A.S.; Bryce, M.R.; Lloyd, J.P.; Petty, M.C.; Kobayashi, K.; Tukada, H. Synthesis of tetrathiafulvalene (TTF) derivatives bearing long alkyl chains. J. Chem. Soc. Chem. Commun. 1988, 1391-1392, doi:10.1039/C39880001391.

10. Meng, H.; Bendikov, M.; Mitchell, G.; Helgeson, R.; Wudl, F.; Bao, Z.; Siegrist, T.; Kloc, C.; Chen, C.H. Tetramethylpentacene: Remarkable absence of steric effect on field effect mobility. Adv. Mater. 2003, 15, 1090-1093.

11. Okamoto, K.; Kawamura, T.; Sone, M.; Ogino, K. Study on liquid crystallinity in 2,9-dialkylpentacenes. Liq. Cryst. 2007, 34, 1001-1007.

12. Kunugi, Y.; Busujima, Y.; Ikari, M.; Okamoto, K.; Ogino, K. Organic field-effect transistors based on 2,9-disubstituted pentacene. ECS Trans. 2008, 16, 273-282.

13. Perepichka, I.F.; Perepichka, D.F. Handbook of Thiophene-based Materials; Wiley: Chichester, UK, 2009.

14. Oliva, M.M.; Casado, J.; Navarrete, J.T.L.; Patchkovskii, S.; Goodson, T.; Harpham, M.R.; de Melo, J.S.S.; Amir, E.; Rozen, S. Do [all]-S,S'-Dioxide Oligothiophenes show electronic and optical properties of oligoenes and/or of oligothiophenes? J. Am. Chem. Soc. 2010, 132, 6231-6242.

15. Alberola, A.; Bosch-Navarro, C.; Gavina, P.; Tatay, S. Synthesis of brominated tetrathiafulvalenes via phosphite-mediated cross-coupling. Synth. Met. 2010, 160, 1797-1799.

16. Fieser, L.F. Organic Synthesses Collected Volume I; Gilman, H., Ed.; Wiley: New York, NY, USA, 1941; pp. 517-519.

17. Fieser, L.F. Organic Experiments; D.C. Heath: Lexington, MA, USA, 1965; pp. 195-200. 
18. Bénard, C.P.; Geng, Z.; Heuft, M.A.; Van Crey, K.; Fallis, A.G. Double diels-alder strategies to Soluble 2,9- and 2,9,6,13-Tetraethynylpentacenes, Photolytic [4+4] Cycloadditions, and pentacene crystal packing. J. Org. Chem. 2007, 72, 7229-7236.

19. Okamoto, T.; Reese, C.; Senatore, M.L.; Tang, M.L.; Jiang, Y.; Parkin, S.R.; Bao, Z. 2,9-Dibromopentacene: Synthesis and the role of substituent and symmetry on solid-state order. Synth. Met. 2010, 160, 2447-2451.

20. Vets, N.; Smet, M.; Dehaen, W. Synthesis and thermolysis of a Diels Alder adduct of pentacene and thiophosgene. Tetrahedron Lett. 2004, 45, 7287-7289.

21. Belen'kii, L.I.; Yakubov, A.P. Stable heteroareniumions-VIII some transformations of alkylthiophenium ions and new synthesis of 2-t-butylthiophene. Tetrahedron 1984, 40, 2471-2477.

22. Pinault, T.; Chérioux, F.; Therrien, B.; Süss-Fink, G. An iterative strategy for the synthesis of oligothiophenes by catalytic cross-coupling reactions. Heteroatom Chem. 2004, 15, 121-126.

23. Kagan, J.; Arora, S.K.; Prakash, I.; Üstünol, A. The synthesis of 2,2':5',3"-terthiophene. Heterocycles 1983, 20, 1341-1345.

24. Tang, M.L.; Reichardt, A.D.; Miyaki, N.; Stoltenberg, R.M.; Bao, Z. Ambipolar, high performance, acene-based organic thin film transistors. J. Am. Chem. Soc. 2008, 130, 6064-6065.

25. Tang, M.L.; Reichardt, A.D.; Wei, P.; Bao, Z. Correlating carrier type with frontier molecular orbital energy levels in organic thin film transistors of functionalized acene derivatives. J. Am. Chem. Soc. 2009, 131, 5264-5273.

26. Meng, H.; Zheng, L.; Lovinger, A.J.; Wand, B.-C.; Patten, P.G.V.; Bao, Z. Oligofluorene-thiophene derivatives as high-performance semiconductors for organic thin film transistors. Chem. Mater. 2003, 15, 1778-1787.

27. Frisch, M.J.; Trucks, G.W.; Schlegel, H.B.; Scuseria, G.E.; Robb, M.A.; Cheeseman, J.R.; Scalmani, G.; Barone, V.; Mennucci, B.; Petersson, G.A.; et al. Gaussian 09, Revision B.01; Gaussian, Inc.: Wallingford, CT, USA, 2009.

28. Yasuda, T.; Goto, T.; Fujita, K.; Tsutsui, T. Ambipolar carrier transport in polycrystalline pentacene thin-film transistors. Mol. Cryst. Liq. Cryst. 2006, 444, 219-224.

29. Batsanov, A.S. Tetrathiafulvalene revisited. Acta Crystallogr. 2006, C62, o501-o504.

30. Mattheus, C.C.; Dros, A.B.; Baas, J.; Meetsma, A.; de Boer, J.L.; Palstra, T.M. Polymorphism in pentacene. Acta Crystallogr. 2001, C57, 939-941.

31. Mori, T.; Kobayashi, A.; Sasaki, Y.; Kobayashi, H.; Saito, G.; Inokuchi, H. The intermolecular interaction of tetrathiafulvalene and bis(ethylenedithio)tetrathiafulvalene in organic metals. calculation of orbital overlaps and models of energy-band structures. Bull. Chem. Soc. Jpn. 1984, 57, 627-633.

32. Kojima, H.; Mori, T. Dihedral angle dependence of transfer integrals in organic semiconductors with herringbone structures. Bull. Chem. Soc. Jpn. 2011, 84, 1049-1056.

33. Campbell, R.B.; Robertson, J.M.; Trotter, J. The crystal and molecular structure of pentacene. Acta Crystallogr. 1961, 14, 705-711.

34. Aoyagi, I.; Katsuhara, M.; Mori, T. Syntheses and structures of highly soluble bis(ethylenedithio)tetrathiafulvalene molecules with alkyl chains. Sci. Technol. Adv. Mater. 2004, $5,443-447$. 
35. Shitzkovsky, S.; Weger, M.; Gutfreund, H. Band structure of TTF-TCNQ. J. Phys. (Paris) 1978, 39, 711-717.

36. Kunugi, Y.; Takimiya, K.; Yamane, K.; Yamashita, K.; Aso, Y.; Otsubo, T. Organic field-effect transistor using oligoselenophene as an active layer. Chem. Mater. 2003, 15, 6-7.

37. Takimiya, K.; Kunugi, Y.; Toyoshima, Y.; Otsubo, T. 2,6-Diarylnaphtho[1,8-bc:5,4- $b^{\prime} c^{\prime}$ ]dithiophenes as new high-performance semiconductors for organic field-effect transistors. J. Am. Chem. Soc. 2005, 127, 3605-3612.

38. Scott, B.A.; La Placa, S.J.; Torrance, J.B.; Silverman, B.D.; Welber, B.J. The crystal chemistry of organic metals. Composition, structure, and stability in the tetrathiafulvalenium-halide systems. J. Am. Chem. Soc. 1977, 99, 6631-6639.

39. Fourmigué, M.; Reinheimer, E.W.; Dunbar, K.R.; Auban-Senzier, P.; Pasquier, C.; Coulon, C. A series of strongly one-dimensional organic metals with strictly uniform stacks: (o-DMTTF $)_{2} \mathrm{X}$ (X = Cl, Br, I). Dalton Trans. 2008, 4652-4658, doi:10.1039/B805511D.

40. Yamamoto, H.M.; Kosaka, Y.; Maeda, R.; Yamaura, J.; Nakano, A.; Nakamura, T.; Kato, R. Supramolecular insulating networks sheathing conducting nanowires based on organic radical cations. ACS Nano 2008, 2, 143-155.

41. Chappell, J.S.; Bloch, A.N.; Bryden, W.A.; Maxfield, M.; Poehler, T.O.; Cowan, D.O. Degree of charge transfer in organic conductors by infrared absorption spectroscopy. J. Am. Chem. Soc. 1981, 103, 2442-2443.

42. Kagoshima, S.; Ishiguro, T.; Anzai, H. X-ray scattering study of phonon anomalies and superstructures in TTF-TCNQ. J. Phys. Soc. Jpn. 1976, 41, 2061-2071.

43. Sheldrick, G.M. A short history of SHELX. Acta Crystallogr. 2008, A64, 112-122.

44. Altomare, A.; Cascarano, G.; Giacovazzo, C.; Guagliardi, A.; Burla, M.C.; Polidori, G.; Camalli, M. SIR92-A program for automatic solution of crystal structures by direct methods. J. Appl. Crystallogr. 1994, 27, 435.

(C) 2012 by the authors; licensee MDPI, Basel, Switzerland. This article is an open access article distributed under the terms and conditions of the Creative Commons Attribution license (http://creativecommons.org/licenses/by/3.0/). 